\title{
Exercise capacity and heart rate recovery response to exercise in morbidly obese female patients with obstructive sleep apnoea syndrome
}

\author{
Carlos Carpio ${ }^{1}$, Ana Santiago ${ }^{1}$, María Gómez-Mendieta ${ }^{1}$, Paloma Caballero ${ }^{2}$, Antonio Martín-Duce ${ }^{3}$, Francisco Gómez \\ de Terreros ${ }^{4}$, Rodolfo Álvarez-Sala ${ }^{1}$ \\ ${ }^{1}$ Department of Respiratory Medicine, La Paz University Hospital. Health Research Institute (IdiPAZ), Madrid, Spain; University Autonoma of Madrid \\ ${ }^{2}$ Department of Radiology, University Hospital La Princesa, Madrid, Spain; Autonomous University of Madrid \\ ${ }^{3}$ Department of Surgery, University Hospital Príncipe de Asturias, University Alcalá de Henares \\ ${ }^{4}$ Department of Respiratory Medicine, Hospital San Pedro Alcántara, Cáceres \\ *Author for correspondence: Carlos Carpio (carlinjavier@hotmail.com)
}

\section{ABSTRACT}

INTRODUCTION: To study exercise capacity and heart rate (HR) recovery after peak exercise in morbidly obese female patients with obstructive sleep apnoea (OSA).

METHODS: Twenty-four morbidly obese female patients (36.17 \pm 9.20 years and $45.20 \pm 5.41 \mathrm{~kg} . \mathrm{m}-2)$ newly diagnosed with OSA underwent cardiopulmonary exercise testing (CPET) for assessment of peak oxygen uptake (V'O2) and heart rate (HR) recovery at 30,60 and 90 seconds. Comparisons were made between mild (apnoea-hypopnea index $[\mathrm{AHI}]<15 \mathrm{~h}-1)$ and moderate-to-severe $(\mathrm{AHI} \geq 15 \mathrm{~h}-1)$ OSA.

RESULTS: For the entire study population, peak V'O2 was $15.58 \pm 2.44 \mathrm{ml} . \mathrm{min}-1 . \mathrm{kg}-1$. No differences in peak V'O2 were found between moderate-to-severe and mild OSA (16.11 \pm 2.37 vs. $15.19 \pm 2.50 \mathrm{ml}$.min-1.kg-1, p=.371, respectively). HR recovery registered at any time after the peak workload also did not differ between both groups. Nonetheless, the percentage of HR decrease at 90 seconds of recovery time was almost statistically significantly lower in the patients with moderate-to-severe OSA $(p=.073)$, and it was negatively correlated with the oxygen desaturation index $(r=-0.679, p=.044)$.

CONCLUSION: Exercise capacity is not different between patients with mild and moderate-to-severe OSA. Nevertheless, patients with moderate-to-severe OSA tend to have a slower HR recovery response to exercise than those with milder OSA. Finally, the oxygen desaturation index is related to this slower chronotropic response.

Keywords: Obstructive sleep apnoea, Exercise test, Female, Heart rate, Obesity.

Received March 20, 2017; Accepted May 11, 2017; Published May 23, 2017.

Copyright: (c) 2017 Authors. This is an open-access article distributed under the terms of the Creative Commons Attribution License, which permits unrestricted use, distribution, and reproduction in any medium, provided the original author and source are credited.

Editor: Javier Jareño

Cite as: Carpio C., Santiago A., Gómez-Mendieta M., Caballero P., Martín-Dulce A., Gómez de Terreros F., Álvarez-Sala R. Exercise capacity and heart rate recovery response to exercise in morbidly obese female patients with obstructive sleep apnoea syndrome. IBJ Plus 2017 1(1):e0004.

Funding: The author(s) declared that no grants were involved in supporting this work.

Competing Interests: The authors have declared that no competing interests exist. 


\section{Introduction}

Exercise capacity reflects the ability to perform activities of daily living that require aerobic metabolism, and its assessment provides diagnostic and prognostic information for several respiratory and cardiovascular diseases (1). The impact of obstructive sleep apnoea (OSA) on exercise capacity remains unclear, given some studies have shown that this disorder reduces exercise capacity (2-6), whereas others have found no differences in exercise capacity between OSA and non-OSA populations (7-12).

Several factors impact aerobic capacity, as measured by cardiopulmonary exercise testing (CPET). Severe obesity reduces exercise capacity because fat mass interferes with cardiac and respiratory function (13). Obesity is also considered a major risk factor for OSA because there is a tendency for OSA to worsen with significant weight gain (14). A person's sex also has an influence on exercise capacity, which could be at least 20\%-40\% lower in women than in men (15). These variables have not always been considered, however, when interpreting the results of studies that have evaluated exercise capacity in patients with OSA $(2-10,12)$. Moreover, these reports have included only a small number of women; therefore, their results might not extend to this population. Furthermore, only one study has included CPET measurements obtained from subjects with morbid obesity (3).

A delayed heart rate (HR) recovery after CPET is considered a predictor of overall mortality (16). Some studies have shown that patients with OSA have an attenuated HR recovery that is dependent on OSA severity $(3,5,11,17)$. A possible mechanism involves reduced parasympathetic activity, which is observed in patients with OSA during the recovery phase of exercise (11). However, HR recovery in patients with OSA has primarily been analysed in men because previous studies have included only a small number of women $(3,11,17)$. This bias is of particular importance, given HR recovery might be decreased in women compared with men in some populations, such as those affected with heart disease (18). Because previous studies have been performed primarily on men, it is important to also know how OSA impacts HR recovery in women.

Therefore, the purpose of this study was to study exercise capacity and cardiovascular response to CPET in morbidly obese female patients with OSA.

\section{Materials and Methods}

\section{Study subjects}

Twenty-four morbidly obese female patients newly diagnosed with OSA were studied from January 2005 to December 2006. All were on a waiting list for bariatric surgery due to morbid obesity. Inclusion criteria were as follows: apnoea-hypopnea index (AHI) $>5$ h- 1 found in the outpatient sleep register, age between 18 and 65 years, body mass index (BMI) $\geq 40$ kg.m-2 and female sex. Exclusion criteria were heart, renal, liver or neurologic disease; pregnancy; unwillingness or inability to perform testing procedures; previous OSA diagnosis; previous CPAP use; and chronic oxygen therapy. The study was approved by the Institutional Ethics Committee at $\mathrm{La}$ Paz University hospital and Principe de Asturias University Hospital, both located in Madrid, Spain. All the patients provided their written informed consent prior to any procedure.

At baseline, all the patients' anthropometric data was recorded and an Epworth somnolence scale was completed.

\section{Sleep register}

For every patient, an overnight sleep study was performed using a portable device (Breas SC-20, Breas Medical S.L., Mölnlyke, Sweden), which is a level 3 sleep monitoring diagnostic tool. Tracings were initiated at approximately 11:00 PM and were terminated at 6:00 AM, allowing at least 7 hours of sleep recording. The device recorded airflow by nasal pressure cannula, respiratory effort by thoracic and abdominal bands and oxygenation by pulse oximetry, as well as snoring and body position. All tracings were analysed manually by the same pulmonologist, and respiratory events were scored according to the American Academy of Sleep Medicine (19). Apnoea was defined as a complete cessation in airflow $\geq 10$ seconds, and hypopnea as a significant decrease in the amplitude of recorded airflow that lasted $\geq 10$ seconds that was associated with oxygen desaturation $>3 \%$. From these measurements, AHI was calculated as the total number of apnoea and hypopnea events divided per hour of study. We also registered the oxygen desaturation index, the lowest oxygen saturation and the percentage of time spent asleep with oxygen saturation below $90 \%$.

\section{Cardiopulmonary exercise test}

All the patients completed a symptom-limited progressive CPET with an Ergobex cycle ergometer (Bexen, Madrid, Spain). Expired gases and ventilatory parameters were analysed breath-by-breath (sensor Oxycon Alpha, Jaëger, Germany). Aerobic capacity (V'O2), heart rate (HR), 12-lead electrocardiogram and oxygen saturation were continuously recorded throughout the test. After one minute of unloaded cycling, the workload was increased by 20 watt.min- 1 until the patient could not continue cycling, at which moment peak exercise variables were registered. Predicted maximal heart rate (MHR) was calculated using equation 220-age (20). After achieving the peak workload, participants spent 90 seconds in a cool-down 
period at no workload, and HR data were registered three times (HR1, HR2 and HR3 were registered at 30, 60 and 90 seconds after peak workload, respectively). HR recovery was assessed as HR1, HR2 and HR3 and also as a percentage decrease of MHR at HR1, HR2 and HR3.

\section{Statistical analysis}

The patients were classified according to AHI in two groups: mild OSA (AHI 5-15 h-1) and moderateto-severe OSA (AHI $\geq 15$ h-1). Statistical analyses were first performed on the whole population, and then comparisons between groups were performed. The quantitative variables were expressed as means with standard deviation. For the categorical variables, frequencies and proportions were used. To compare two means, an unpaired t-test or the Mann-Whitney U test was used, as appropriate. Homoscedasticity was assessed by the Kolmogorov-Smirnov test. Correlations between the sleep register and CPET variables were evaluated using Pearson's correlation coefficients. If differences were not normally distributed, Spearman's correlation was employed. Statistical significance was set at a $\mathrm{p}$-value $\leq .05$. The data were analysed using SPSS, v.10.1 (Chicago, IL, USA).

\section{Results}

\section{Baseline characteristics}

A total of twenty-four morbidly obese female patients were included. Mean age and mean BMI were $36.17 \pm 9.20$ years and $45.20 \pm 5.41$ kg.m-2, respectively. Presented in Table 1 are the sleep data for the entire study population. Mild, moderate and severe OSA was detected in 14 (58.30\%), $3(8.60 \%)$ and 7 (29.20\%) patients, respectively.

Mean peak workload in CPET was $97.72 \pm 17.23$ watts, and mean peak V'O2 was $15.58 \pm 2.44$ ml.min1.kg-1. At maximal workload, the HR was $142 \pm 19.14$ beats.min-1 and during the recovery period, the HR decreased $8.08 \% \pm 3.76 \%, 14.14 \% \pm 9.17 \%$ and $14.83 \% \pm 4.11 \%$ from MHR at 30, 60 and 90 seconds after maximal workload, respectively (Table 1).

\section{Cardiopulmonary exercise testing according to severity of OSA}

No differences were seen between groups with respect to age and BMI. As expected, patients with moderate-to-severe OSA had a higher AHI ( $p<.001)$ and oxygen desaturation index than those with mild OSA $(\mathrm{p}<.001)$.

Concerning the CPET results, peak workload was not different between groups. Interestingly, peak V'O2 measured in moderate-to-severe OSA was not statistically different from that of patients with mild OSA $(16.11 \pm 2.37$ vs. $15.19 \pm 2.50$ ml.min-1.kg-1, $\mathrm{p}=.371$ ). Additionally, both groups achieved similar
MHR during CPET and no differences were found in HR recovery between patients with moderate-to-severe and mild OSA at 30, 60 and 90 seconds after peak workload. Nevertheless, the patients with moderate-tosevere OSA had an almost statistically significantly lower percentage decrease of HR at HR3 compared with patients with mild OSA ( $\mathrm{p}=.073$ ) (Table 2).

\section{Correlations between sleep register and cardiopulmonary exercise testing}

We searched for correlations between sleep events and CPET results. Cross-sectional correlations between V'O2 and AHI or the oxygen desaturation index were not significant. With respect to HR recovery, the percentage decrease of MHR at HR3 was negatively correlated with the oxygen desaturation index ( $\mathrm{r}=-$ $0.679, \mathrm{p}=.044)$ and it showed an almost significant correlation with AHI ( $\mathrm{r}=-0.655, \mathrm{p}=.056)$ (Table 3$)$.

\section{Discussion}

In morbidly obese female patients with OSA, peak V'O2 recorded for patients with mild OSA is not different from that recorded for patients with moderateto-severe OSA. In addition, HR recovery after peak exercise is similar in both groups, but patients with severe OSA tend to demonstrate a slower chronotropic recovery.

Several studies have reported that exercise capacity in patients with OSA is not different from that registered in healthy subjects (7-12,21). However, these results conflict with many other reports that have described higher maximal $\mathrm{V}^{\prime} \mathrm{O} 2$ in non-OSA than in OSA populations (2-6,22). Reinforcing this last observation, some studies have shown that AHI is inversely correlated with peak V'O2 during CPET $(3,5,22,23)$. Nevertheless, other factors have also been implicated in the exercise capacity of patients with OSA, such as age, BMI, body weight and sex $(2,10,22-$ 24). Rizzi et al. (10) compared response to CPET in four groups of patients (OSA/controls and lean/obese subjects) and found that maximal V'O2 did not differ between patients with OSA and controls in both obese and lean patients. However, maximal V'O2 was lower in patients with obesity (OSA and controls) than in lean subjects. Also, Butner et al. (22) reported lower peak $\mathrm{V}^{\prime} \mathrm{O} 2$ in patients with moderate-to-severe OSA than in those with milder OSA or in healthy patients, but these differences were not detected when this variable was controlled for body weight and age.

Several reports have evaluated exercise capacity in obese patients with OSA $(2,6-8,10,12)$, but only one focused on morbidly obese subjects. Vanhecke et al. (3) compared CPET results from 42 morbidly obese (BMI $\geq 35 \mathrm{~kg} . \mathrm{m}-2$ ) patients with OSA and 50 of these without OSA and found a decreased peak V'O2 in the patients with OSA. It is noteworthy that the V'O2 measured in our population was lower than that reported by 
Vanhecke et al. (3) in their OSA group. These differences might be explained by the fact that we included only female patients, in contrast to the study by Vanhecke et al. (3), in which almost one-third of the enrolled population was male. It is known that $\mathrm{V}^{\prime} \mathrm{O} 2$ is lower in women than in men due to their lesser height, lower blood haemoglobin concentration and smaller skeletal muscles, so these sex differences might have affected the V'O2 in our report (15).

In addition to obesity, other factors could affect exercise capacity in patients with OSA. For instance, symptoms such as leg discomfort or dyspnoea during CPET could limit maximal exercise capacity. The impairment of glycolytic metabolism and the structural and metabolic changes in the skeletal muscles of patients with OSA could explain the leg discomfort experienced during the test (25). Cardiac dysfunction could also be responsible for exercise limitation, given reduced peak V'O2 in patients with OSA has been linked to lower right ventricular ejection fraction, reduced cardiac output and reduced oxygen pulse $(2,9)$. Alonso-Fernández et al. (9) demonstrated that CPAP therapy for 3 months was associated with significant improvements in various indexes of left ventricular systolic function response to exercise such as cardiac output and stroke volume. Finally, sleep fragmentation and excessive diurnal somnolence of those with OSA could be related to decreased daily activity and lack of fitness, resulting in submaximal efforts during CPET (2).

The cardiovascular response to exercise in patients with OSA was reported to be attenuated in several studies $(3,5,7,11)$. Patients with OSA have lower HR recovery after peak exercise compared with healthy individuals, and this impaired chronotropic response is directly related to the severity of $\operatorname{OSA}(4,11)$. Although our results did not show statistical differences in HR recovery between both groups, we observed that patients with moderate-to-severe OSA had a tendency to show a blunted HR recovery at 90 seconds after workload and that AHI and DI were almost significantly correlated to this slower HR recovery. This impaired HR recovery could be linked to the increased nocturnal sympathetic activity that patients with OSA show in relation to sleep fragmentation and intermittent hypoxia. Thus, sympathetic overactivity that persists even during wakefulness could reduce sensitization and produce downregulation of cardiac beta adrenergic receptors $(7,26)$.

Our study has some limitations. The first is related to the lack of an obese and a lean control group without OSA. The absence of a control group makes it difficult to accurately evaluate the influence of obesity and OSA on exercise capacity. Another limitation might be related to the fact that we only used clinical evaluations to rule out heart disease in our population. Heart disorders could impair exercise capacity measured during a CPET, and exercise capacity is also considered a prognostic factor in ischemic and dilated cardiomyopathies. All the patients in our study had a nonpathological electrocardiogram because they were on the waiting list for bariatric surgery, so these procedures (clinical evaluation and electrocardiogram) helped us detect important cardiac disorders. As a third limitation, we are not able to confirm associations between sympathetic overactivity and HR recovery because we did not measure sympathetic activity.

In conclusion, in our study, morbidly obese female patients exercise capacity was not different between patients with mild OSA and those with moderate-tosevere OSA. However, the patients with moderate-tosevere OSA tended to have a slower HR recovery response to exercise after they achieved a peak workload.

\section{References}

[1] Arena R, Myers J, Williams MA, Gulati M, Kligfield P, Balady GJ, et al. Assessment of functional capacity in clinical and research settings: a scientific statement from the American Heart Association Committee on Exercise, Rehabilitation, and Prevention of the Council on Clinical Cardiology and the Council on Cardiovascular Nursing. Circulation 2007;116:329-343.

[2] Lin C-C, Hsieh W-Y, Chou C-S, Liaw S-F. Cardiopulmonary exercise testing in obstructive sleep apnea syndrome. Respir Physiol Neurobiol 2006;150:27-34.

[3] Vanhecke TE, Franklin BA, Zalesin KC, Sangal RB, deJong AT, Agrawal V, et al. Cardiorespiratory fitness and obstructive sleep apnea syndrome in morbidly obese patients. Chest 2008; 134:539-545.

[4] Grote L, Hedner J, Peter JH. The heart rate response to exercise is blunted in patients with sleep-related breathing disorder. Cardiology 2004;102:93-99.

[5] Mansukhani MP, Allison TG, Lopez-Jimenez F, Somers VK, Caples SM. Functional aerobic capacity in patients with sleep-disordered breathing. Am J Cardiol 2013;111:1650-1654.

[6] Beitler JR, Awad KM, Bakker JP, Edwards BA, DeYoung P, Djonlagic I, et al. Obstructive sleep apnea is associated with impaired exercise capacity: a cross-sectional study. J Clin Sleep Med 2014;10:1199-1204.

[7] Kaleth AS, Chittenden TW, Hawkins BJ, Hargens TA, Guill SG, Zedalis D, et al. Unique cardiopulmonary exercise test responses in overweight middle-aged adults with obstructive sleep apnea. Sleep Med 2007;8:160-168.

[8] Tryfon S, Stanopoulos I, Dascalopoulou E, Argyropoulou P, Bouros D, Mavrofridis E. Sleep 
apnea syndrome and diastolic blood pressure elevation during exercise. Respiration 2004;71:499-504.

[9] [Alonso-Fernández A, García-Río F, Arias MA, Mediano O, Pino JM, Martínez I, et al. Obstructive sleep apnoea-hypoapnoea syndrome reversibly depresses cardiac response to exercise. Eur Heart J 2006;27:207-215.

[10] Rizzi CF, Cintra F, Mello-Fujita L, Rios LF, Mendonca ET, Feres MC, et al. Does Obstructive Sleep Apnea Impair the Cardiopulmonary Response to Exercise? Sleep 2013;36:547-553.

[11] Hargens TA, Guill SG, Zedalis D, Gregg JM, Nickols-Richardson SM, Herbert WG. Attenuated heart rate recovery following exercise testing in overweight young men with untreated obstructive sleep apnea. Sleep 2008;31:104-110.

[12] Maeder MT, Ammann P, Münzer T, Schoch OD, Korte W, Hürny $\mathrm{C}$, et al. Continuous positive airway pressure improves exercise capacity and heart rate recovery in obstructive sleep apnea. Int J Cardiol 2009;132:75-83.

[13] Serés L, López-Ayerbe J, Coll R, Rodríguez O, Manresa JM, Marrugat J, et al. Cardiopulmonary function and exercise capacity in patients with morbid obesity. Rev Esp Cardiol 2003;56:594600.

[14] Newman AB. Progression and regression of sleep-disordered breathing with changes in weight. Arch Intern Med 2005;165:2408-2413.

[15] Shephard RJ. Exercise and training in women, Part I: Influence of gender on exercise and training responses. Can J Appl Physiol 2000;25:19-34.

[16] Cole CR, Blackstone EH, Pashkow FJ, Snader CE, Lauer MS.Heart-rate recovery immediately after exercise as a predictor of mortality. N Engl J Med 1999;341:1351-1357.

[17] Maeder MT, Münzer T, Rickli H, Schoch OD, Korte W, Hürny C, et al. Association between heart rate recovery and severity of obstructive sleep apnea syndrome. Sleep Med 2008;9:753761.
[18] Kligfield P, McCormick A, Chai A, Jacobson A, Feuerstadt P, Hao SC. Effect of age and gender on heart rate recovery after submaximal exercise during cardiac rehabilitation in patients with angina pectoris, recent acute myocardial infarction, or coronary bypass surgery. Am J Cardiol 2003;92:600-603.

[19] Sleep-related breathing disorders in adults: recommendations for syndrome definition and measurement techniques in clinical research. The Report of an American Academy of Sleep Medicine Task Force. Sleep 1999;22:667-689.

[20] American Thoracic Society, American College of Chest Physicians. ATS/ACCP Statement on cardiopulmonary exercise testing. Am J Respir Crit Care Med 2003;167:211-277.

[21] Rizzi CF, Cintra F, Risso T, Pulz C, Tufik S, de Paola A, et al. Exercise capacity and obstructive sleep apnea in lean subjects. Chest 2010;137:109_ 14.

[22] Butner KL, Hargens TA, Kaleth AS, Miller LE, Zedalis D, Herbert WG. Association of obstructive sleep apnea severity with exercise capacity and health-related quality of life. N Am J Med Sci 2013;5:362-366.

[23] Ucok K, Aycicek A, Sezer M, Genc A, Akkaya M, Caglar V, et al. Aerobic and anaerobic exercise capacities in obstructive sleep apnea and associations with subcutaneous fat distributions. Lung 2009;187:29-36.

[24] Cintra F, Poyares D, Rizzi CF, Risso TT, Skomro $\mathrm{R}$, Montuori E, et al. Cardiorespiratory response to exercise in men and women with obstructive sleep apnea. Sleep Med 2009;10:368-373.

[25] Sauleda J, García-Palmer FJ, Tarraga S, Maimó A, Palou A, Agustí AGN. Skeletal muscle changes in patients with obstructive sleep apnoea syndrome. Respir Med 2003;97:804-810.

[26] Grote L, Kraiczi H, Hedner J. Reduced alpha- and beta(2)-adrenergic vascular response in patients with obstructive sleep apnea. Am J Respir Crit Care Med 2000;162:1480-1487. 
Table 1. Baseline characteristics of the study population

$\begin{array}{lr}\text { Variables } & \text { Value } \\ (\mathrm{n}=24)\end{array}$

Demographics

Age, years

$36.17 \pm 9.20$

Weight, kg

$120.17 \pm 15.74$

Height, m

$1.63 \pm 5.92$

BMI, $\mathrm{kg} / \mathrm{m}^{2}$

$45.20 \pm 5.41$

ESS

$6.25 \pm 4.94$

Sleep registers
AHI, $\mathrm{h}^{-1}$
$21.59 \pm 23.41$
AI, $\mathrm{h}^{-1}$
$7.80 \pm 17.86$
DI, $\mathrm{h}^{-1}$
$22.97 \pm 23.61$
Lowest $\mathrm{SpO}_{2}, \%$
$79.13 \pm 7.40$
Time spent $<90 \%, \%$
$9.83 \pm 16.40$

Peak exercise

Breathing reserve, $\%$

$46.58 \pm 10.77$

Breathing frequency, $\min ^{-1}$

$35.20 \pm 7.18$

Tidal volume, $\mathrm{ml}$

$1821.21 \pm 467.85$

V'E/V' $\mathrm{CO}_{2}$ slope

$28.94 \pm 4.48$

HR slope, $1 . \mathrm{ml}^{-1} \cdot \mathrm{kg}^{-1}$

$9.48 \pm 1.76$

$\mathrm{V}^{\prime} \mathrm{O}_{2}, \mathrm{ml} \cdot \mathrm{min}^{-1} \cdot \mathrm{kg}^{-1}$

$15.58 \pm 2.44$

Work, watts

$97.72 \pm 17.23$

HR, beats. min $^{-1}$

$142 \pm 19.14$

Predicted maximal HR, \%

$74.91 \pm 10.70$

HR recovery at min 0.5 , beats. $\min ^{-1}$

$130.54 \pm 18.08$

$\% \mathrm{HR}$ recovery at $\min 0.5, \%$

$8.08 \pm 3.76$

HR recovery at min 1 , beats. $\min ^{-1}$

$122.82 \pm 23.74$

$\% \mathrm{HR}$ recovery at min $1, \%$

$14.14 \pm 9.17$

HR recovery at min 1.5 , beats. $\min ^{-1}$

$123.57 \pm 16.62$

$\% \mathrm{HR}$ recovery at $\min 1.5, \%$

$14.83 \pm 4.11$

Data are presented as mean $\pm \mathrm{SD}$

\%HR: per cent decrease of maximal heart rate; AHI: apnoea-hypopnea index; AI: apnoea index; BMI: body mass index; DI: oxygen desaturation index; ESS: Epworth somnolence scale; HR: heart rate; $\mathrm{SpO}_{2}$ : pulse oximetry oxygen saturation; VE: minute ventilation; V'CO ${ }_{2}$ : carbon dioxide output; $\mathrm{V}^{\prime} \mathrm{O}_{2}$ oxygen uptake 
Table 2. Comparison between mild and moderate-to-severe obstructive sleep apnoea

\begin{tabular}{|c|c|c|c|}
\hline Variable & $\begin{array}{l}\text { AHI <15 } \\
(\mathrm{n}=14)\end{array}$ & $\begin{array}{c}\mathrm{AHI} \geq 15 \\
(\mathrm{n}=10)\end{array}$ & $95 \% \mathrm{CI}$ \\
\hline Age, years & $35.57 \pm 11.37$ & $37.00 \pm 5.31$ & $-9.48-6.62$ \\
\hline Weight, kg & $117.07 \pm 17.70$ & $124.50 \pm 12.03$ & $-20.85-6.00$ \\
\hline BMI, kg.m $\mathrm{m}^{-2}$ & $44.30 \pm 6.02$ & $46.47 \pm 4.40$ & $-6.82-2.48$ \\
\hline ESS & $7 \pm 4,50$ & $5.50 \pm 5.53$ & $-3.91-6.91$ \\
\hline AHI, $h^{-1}$ & $7.26 \pm 2.20$ & $41.65 \pm 25.06$ & $-52.32--16.44 * *$ \\
\hline AI, $h^{-1}$ & $0,83 \pm 1.27$ & $17.56 \pm 25.14$ & $-30.55--2.89 *$ \\
\hline DI, $h^{-1}$ & $8.8 \pm 4.82$ & $42.74 \pm 25.43$ & $-52.19--15.61 * *$ \\
\hline Lowest $\mathrm{SpO}_{2}, \%$ & $82.70 \pm 4.92$ & $74.50 \pm 7.71$ & $2.71-13.68 * *$ \\
\hline Time spent $<90 \%, \%$ & $2.14 \pm 20.60$ & $4.32 \pm 20.96$ & $-33.54--3.37 *$ \\
\hline Breathing reserve, $\%$ & $47.86 \pm 12.06$ & $44.80 \pm 8.98$ & $-6.31-12.42$ \\
\hline Breathing frequency, $\min ^{-1}$ & $34.07 \pm 5.40$ & $36.80 \pm 9.21$ & $-8.92-3.46$ \\
\hline Tidal volume, 1 & $1837 \pm 526.47$ & $1799.10 \pm 397.59$ & $-372.51-448.31$ \\
\hline $\mathrm{V}^{\prime} \mathrm{E} / \mathrm{V}^{\prime} \mathrm{CO}_{2}$ slope & $28.63 \pm 4.20$ & $29.35 \pm 5.09$ & $-4.65-3.21$ \\
\hline HR slope, $1 . \mathrm{ml}^{-1} \cdot \mathrm{kg}^{-1}$ & $9.92 \pm 1.96$ & $8.90 \pm 1.36$ & $-0.47-2.51$ \\
\hline $\mathrm{V}^{\prime} \mathrm{O}_{2}, \mathrm{ml} \cdot \mathrm{min}^{-1} \cdot \mathrm{kg}^{-1}$ & $15.19 \pm 2.50$ & $16.11 \pm 2.37$ & $-3.03-1.17$ \\
\hline Peak workload, watts & $94.37 \pm 18.40$ & $106.67 \pm 11.54$ & $-38.51-13.93$ \\
\hline HR, beats. $\min ^{-1}$ & $142.86 \pm 22.04$ & $139.67 \pm 11.06$ & $-27.62-34.02$ \\
\hline Predicted maximal HR, $\%$ & $75.75 \pm 12.65$ & $72.67 \pm 1.54$ & $-14.02-20.18$ \\
\hline HR recovery at $\min 0.5$, beats. $\min ^{-1}$ & $129.88 \pm 20.71$ & $132.33 \pm 11.24$ & $-31.59-26.67$ \\
\hline$\% \mathrm{HR}$ recovery at $\min 0.5, \%$ & $9.13 \pm 3.91$ & $5.28 \pm 1.00$ & $-1.48-9.17$ \\
\hline HR recovery at min 1 , beats. $\min ^{-1}$ & $121.12 \pm 27.30$ & $127.33 \pm 12.90$ & $-44.24-31.83$ \\
\hline$\% \mathrm{HR}$ recovery at $\min 1, \%$ & $16.09 \pm 10.11$ & $8.93 \pm 2.45$ & $-6.63-20.93$ \\
\hline HR recovery at $\min 1.5$, beats. $\min ^{-1}$ & $123.17 \pm 16.17$ & $124.34 \pm 14.19$ & $-27.29-24.96$ \\
\hline$\% \mathrm{HR}$ recovery at $\min 1.5, \%$ & $16.69 \pm 3.23$ & $11.14 \pm 3.26$ & $-0.82-11.89$ \\
\hline \multicolumn{4}{|c|}{$\begin{array}{l}\text { \%HR: per cent decrease of maximal heart rate; } \mathrm{AHI} \text { : apnoea-hypopnea index; } \mathrm{AI} \text { : apnoea index; BMI: body mass index; DI: oxygen desaturation } \\
\text { index; ESS: Epworth somnolence scale; } \mathrm{HR} \text { : heart rate; } \mathrm{SpO}_{2} \text { : pulse oximetry oxygen saturation; VE: minute ventilation; } \mathrm{V}^{\prime} \mathrm{CO}_{2} \text { : carbon dioxide } \\
\text { output; } \mathrm{V}^{\prime} \mathrm{O}_{2} \text { oxygen uptake }\end{array}$} \\
\hline
\end{tabular}


Table 3. Correlations between sleep registers and cardiopulmonary exercise testing

\begin{tabular}{lcccc}
\hline Variable & \multicolumn{2}{c}{ AHI } & & DI \\
& $\mathrm{r}$ & $\mathrm{p}$ & $\mathrm{r}$ & $\mathrm{P}$ \\
\hline Predicted maximal HR, \% & -0.067 & 0.844 & -0.062 & 0.856 \\
\%HR recovery at min $0.5, \%$ & -0.468 & 0.147 & -0.414 & 0.206 \\
\%HR recovery at min 1,\% & -0.406 & 0.216 & -0.381 & 0.248 \\
\%HR recovery at min 1.5, \% & -0.655 & 0.056 & -0.679 & 0.044 \\
\hline \%HR: per cent decrease of maximal heart rate; AHI: apnoea-hypopnea index; DI: oxygen desaturation index & & \\
\end{tabular}

